\title{
A PRODUÇÃO DO ESPAÇO COMO RESISTÊNCIA AO CAPITAL
}

\section{THE PRODUCTION OF SPACE AS RESISTANCE TO THE CAPITAL}

Fábio Rodrigues da Costa

UNESPAR - Campo Mourão - PR

fabiorcmestrado@bol.com.br

\begin{abstract}
RESUMO
Seguramente o espaço é aceito pela maioria dos geógrafos como o objeto de estudo de sua ciência. Contudo, a palavra vem carregada de um grande número de significados, o que torna necessário maiores esclarecimentos. No presente artigo procuramos discutir o conceito de produção do espaço com o objetivo de entender a ação do capital em busca de reprodução ampliada e a resistência social contrária a esse processo. Se a ação do capital tem por principio a produção do espaço procurando ampliação, dialeticamente, existe resistência por parte de alguns grupos da sociedade. Como exemplo de produção do espaço como resistência ao capital apontamos alguns movimentos como: Movimento dos Trabalhadores Rurais Sem Terra, Movimento dos Trabalhadores Sem Teto, Associação de Moradores e a Economia Solidária.
\end{abstract}

Palavras-chave: Produção do espaço, Capital, Resistência.

\begin{abstract}
Undoubtly space is accepted and taken for granted by most geographers as the object of study of their science. However, more and more the word space has been loaded with a number of meanings, which makes it necessary further clarification. In this paper we made an attempt to discuss the concept of production of space aiming at understanding of the action of capital looking deep and carefully for expanded reproduction and social resistance against this process. If the action of capital has as principle the production of space looking for expansion, dialectically there is a kind of resistance from some groups within the society. Landless Rural Workers Moviment, Homeless Workers Movement, Residents Association and Solidarity Economy are good examples of production of space as resistence to capital.
\end{abstract}

Keywords: Production of space. Capital. Resistance. 


\section{INTRODUÇÃO}

A discussão sobre o espaço como objeto de estudo da geografia não é nova, a temática é recorrente em um elevado número de estudos que procuram delinear o campo de atuação do geógrafo e esclarecer o potencial do seu objeto de estudo. Porém, uma pergunta é necessária: até onde os teóricos avançaram no entendimento do conceito de espaço? Na epistemologia da geografia encontramos que o homem como ser social foi separado da natureza. Uma natureza compreendida a partir de suas potencialidades físicas (relevo, solo, rios, vegetação, etc.). Assim, por conseguinte, o espaço entendido como fixo e estático, ou seja, palco das atuações sociais também foi separado da sociedade. Inicialmente a geografia aparece como a ciência da localização e da descrição da superfície terrestre. A partir da década de 1970 o conceito de espaço fixo passa a ser profundamente questionado pela vertente crítica da geografia, em particular pela corrente marxista. Face as grandes desigualdades sociais a geografia não podia mais entender o espaço apenas como palco. O movimento, a dinâmica e a contradição são inseridos no argumento teórico estabelecendo as bases para o conceito de produção do espaço.

O que se pretende com o presente artigo é afirmar a importância do conceito de espaço para a geografia e demostrar o potencial e a atualidade da abordagem marxista sobre produção do espaço a partir das premissas da dialética.

Os novos fluxos de informação e de mercadorias oriundos da mundialização, característica do período atual do capitalismo em sua fase financeira permitem ao capital se mover com grande velocidade em busca por ampliação. Tal processo necessita eminentemente de espaço, ou, mais especificamente, produzir e reproduzir o espaço como forma e expansão e dominação. Porém, contraditoriamente, o espaço também se produz e reproduz como resistência aos anseios do capital. É isso que pretendemos demonstrar no transcorrer do texto.

\section{EM BUSCA DA HISTÓRIA}


Iniciamos a discussão buscando apresentar a compreensão de alguns autores sobre o materialismo histórico dialético, concepção que norteia a temática produção do espaço. Para Frigotto (1989, p. 73), é uma postura, uma concepção de mundo "um método que permite uma apreensão radical (que vai à raiz) da realidade e, enquanto práxis, isto é, unidade de teoria e prática na busca da transformação e de novas sínteses no plano do conhecimento e no plano da realidade histórica." Na visão de Löwy (2000, p. 59) o pensamento de Marx “inaugura não uma 'ciência da história' - que já existia antes dele - mas uma nova concepção de mundo, que permanece uma referência necessária para todo pensamento e ação emancipadores."

Lefebvre (1983) escreve que o método dialético não é um fenômeno intelectual, um fato cultural entre outros que viria ajuntar-se aos existentes e complicar um pouco mais uma cultura já complicada. Ele vem ordenar, desobstruir e organizar a consciência do mundo e do homem. Conforme Moraes e Costa (1999), diz respeito às contradições do real, a concepção de mundo e de movimento, deve ser radical e ter por finalidade a transformação da realidade. Os referidos autores concordam que o materialismo histórico e dialético é uma concepção de mundo. Mas o que é uma concepção de mundo?

É uma visão de conjunto da natureza e do homem, uma doutrina completa. Num sentido, uma concepção do mundo constitui o que chamamos tradicionalmente uma filosofia. Contudo, a expressão possui um significado mais amplo do que o termo filosofia. Em primeiro lugar, toda a concepção do mundo implica uma ação, isto é, algo mais do que uma "atitude filosófica". [...] $\mathrm{Na}$ concepção marxista do mundo, a ação define-se racionalmente, em conexão com o conjunto doutrinário, e determina, declaradamente, um programa político. (LEFEBVRE, 1979, p. 10).

O método marxista recusa uma hierarquia exterior aos indivíduos como na concepção de mundo cristã. Também não se encerra na consciência do indivíduo e no exame da consciência isolada que se segue na concepção individualista. Na dialética materialista o que se verifica é a contradição no homem e na sociedade. Contradição significa também "problemas a solucionar, dificuldades, obstáculos - portanto, luta e ação -, mas, também, possibilidade de vitória, de passo à frente, de progresso. Por 
conseguinte, o marxismo evita o pessimismo definitivo, bem como o otimismo fácil." (LEFEBVRE, 1979, p. 12).

É demasiadamente importante entender o procedimento de interpretação do real proposto, pois sua compreensão permite a ampliação da capacidade de análise crítica, sem a qual, corremos o risco de não desvendar a essência. Marx e Engels (2007, p. 94), ao criticarem Hegel e a filosofia alemã do seu período esclarecem que é necessário partir da realidade: "totalmente ao contrário da filosofia alemã, que desce do céu à terra, aqui se eleva da terra ao céu." Os autores enfatizam a necessidade das investigações partirem do que é material e empírico.

Assim, para compreender a essência da realidade são necessários os procedimentos de abstração e concreção, visto que é preciso romper com as aparências para atingir a verdadeira essência. Lukács (1999), por sua vez relata que como ponto de partida temos um vasto processo de abstração, a partir do qual - por meio da dissolução paulatina das abstrações metodologicamente inevitáveis - abre-se o caminho que conduz o pensamento, etapa após etapa, a apreender a totalidade em sua concreticidade clara e articulada.

Através dos sucessivos procedimentos de abstração é que paulatinamente o pensamento rompe com as aparências do fenômeno e radicaliza, ou seja, atinge a essência - que é o concreto pensado em sua totalidade.

Lukács (1979, p. 46), escreve que para se chagar à explicação concreta é necessário iniciar a investigação a partir de elementos de importância central. Argumenta que "Marx, em O Capital, examinou como categoria inicial, como ‘elemento' primário, o valor." Fez isso porque essa categoria "ilumina plenamente o que de mais importante existe na estrutura do ser social, ou seja, o caráter social da produção." Ao fazer isso, Marx radicaliza, ou seja, desvenda a realidade oculta por detrás das aparências. O valor, produzido através do trabalho humano, é a categoria central inicial na discussão e Marx o discute a partir do valor de uso e valor de troca.

A relação entre teoria e ação (práxis) também é fundamental. Na XI tese sobre Feuerbach, Marx enfatiza sua preocupação com a necessidade de transformar a sociedade: "Os filósofos apenas interpretam o mundo de maneiras diferentes; porém, o que importa é transforma-lo.” (MARX, 2009, p. 126). É um ato teleológico porque 
envolve uma finalidade, um objetivo final que precede a própria realização, ou seja, a transformação é um "pré-requisito" que o pesquisador deve ter ao iniciar a pesquisa.

Assim, a contradição básica, raiz das outras contradições é entre o caráter necessariamente social do trabalho humano e a propriedade privada dos meios de produção. O trabalho do homem apresenta um caráter social e não individual. Já a propriedade dos meios de produção, a partir da acumulação primitiva e da expropriação e espoliação, adquirem caráter privado e não mais coletivo. Daí emerge uma profunda contradição: o trabalho é coletivo mais a propriedade é privada.

O método também trabalha com a análise histórica, ou seja, para a compreensão do fenômeno é necessário entender as relações sociais que vão sendo estabelecidas e que conduzem a atual configuração da sociedade. A análise histórica e o movimento estão fortemente presentes na obra de Marx, o que é evidenciado por Jean Kessler (2007):

Real é, pois, o que é histórico. Tudo o que pretende escapar à história e impor-se como uma verdade eterna é, para Marx, necessariamente falso. Toda categoria econômica, toda lei, todo conceito econômico (por exemplo, a propriedade privada) é abstração das relações sociais e não é verdadeiro 'senão enquanto essas relações subsistem'. Não são, pois, verdadeiras senão transitoriamente, visto que nada dura eternamente e que o movimento, a troca, a evolução conflitual são a lei de tudo o que existe. (KESSLER, 2007, p. 30).

A realidade é um momento histórico e tudo aquilo que pretende se impor como verdade eterna e imutável é falso. O movimento, a transformação e o conflito fazem parte da existência.

É evidente a preocupação em desmistificar a realidade como algo dado, pronto, estático, sem movimento. A realidade é um produto social, fruto das relações estabelecidas entre os homens e entre homem e natureza. As relações são históricas, estão em movimento e, portanto, são transitórias. Conforme Lefebvre (1979, p. 50) “O real não é estático e absolutamente acabado. É devir e, portanto, possibilidade."

Para Löwy (2000) a maior contribuição de Marx está no seu novo método de pensamento e de ação que cortou o nó da filosofia praticada na sua época e inovou através da práxis revolucionária: 
Em que consiste está nova visão de mundo, inaugurada pelas Teses sobre Feuerbach de 1845? A melhor definição me parece ainda aquela de Gramsci: filosofia da práxis. Este conceito tem a grande vantagem de destacar a descontinuidade do pensamento marxista em relação aos discursos filosóficos dominantes: rejeitando tanto o velho materialismo da filosofia das luzes - mudar as circunstâncias para libertar o homem (com seu corolário político lógico: o apelo ao déspota esclarecido ou a uma elite virtuosa) - quanto o idealismo neohegeliano (libertar a consciência humana para mudar a sociedade), Marx cortou o nó górdio da filosofia de sua época proclamando (terceira Teses sobre Feuerbach) que na práxis revolucionária coincidem a mudança das circunstâncias e a transformação das consciências. Daí decorre, com rigor e coerência, sua nova concepção de revolução, apresentada pela primeira vez em $A$ ideologia alemã: é por sua própria experiência, no curso de sua própria práxis revolucionária, que os explorados e os oprimidos podem quebrar ao mesmo tempo as "circunstancias" exteriores que os aprisionam - o Capital, o Estado - e sua consciência mistificada anterior. (LÖWY, 2000, p. 59-60, grifo do autor).

A realidade a ser atingida através da análise e reconstruída pela exposição (sintética) é uma realidade em movimento. O método de pensamento e de ação de Marx trouxe profundas modificações ao romper com os paradigmas dominantes no período. A práxis revolucionária, a tomada de consciência e a emancipação são necessárias para romper com a exploração que a classe trabalhadora é submetida.

\section{ONDE ENTRA O ESPAÇO OU O FILHO RENEGADO?}

É necessário esclarecer que a contribuição marxista, especialmente até a década de 1960, esteve mais efetivamente preocupada com as questões históricas, sociais, econômicas e políticas do que com a análise espacial. Assim, foi valida a seguinte crítica [...] os marxistas têm-se inclinado a aceitar a concepção burguesa tradicional de espaço como algo efetivamente separado da sociedade [...]. (SMITH, 1988, p. 15).

Harvey (2006a, p. 142) também expõe sua preocupação com relação ao desprezo do espaço nas análises sociais “A questão do espaço e da geografia é uma 'enteada' muito desprezada em toda a teoria social; em parte, suponho, porque sua inclusão tem um efeito entorpecedor nas principais proposições de qualquer corpus de teoria social."

Geo UERJ. Rio de Janeiro - Ano 16, $\mathrm{n}^{\circ} .25$, v. 2, $2^{\circ}$ semestre de 2014, pp.37-56

ISSN: 1415-7543 E-ISSN: 1981-9021

http://www.e-publicacoes.uerj.br/index.php/geouerj 
$\mathrm{O}$ autor argumenta que Marx em seus textos admite a importância do espaço e do lugar. Mas nada disso está realmente integrado em suas formulações teóricas que são poderosas com respeito ao tempo, mas frágeis em relação ao espaço. Porém, as suas obras revelam que a acumulação de capital ocorria num contexto geográfico.

É necessário o aprofundamento teórico das discussões espaciais, mas sem deixar de lado as investigações históricas. Desta madeira é possível ampliar o entendimento da expansão do capitalismo pela superfície terrestre e a produção de desigualdade espacial.

Nossa tarefa é elaborar uma teoria geral das relações espaciais e do desenvolvimento geográfico sob o capitalismo, que possa, entre outras coisas, explicar a importância e a evolução das funções do Estado (locais, regionais, nacionais $\mathrm{e}$ supranacionais), do desenvolvimento geográfico desigual, das desigualdades inter-regionais, do imperialismo, do progresso e das formas de urbanização etc. [...]. (HARVEY, 2006a, p. 144).

Através da analise espacial é possível ampliar a visão e a compreensão das contradições e do desenvolvimento geográfico desigual presentes na ação do capital e do Estado ao (re)produzir o espaço.

Harvey (2006a, p. 144) trouxe importante contribuição ao inserir o espaço na análise marxista e avança ainda mais ao afirmar que "A geografia histórica do capitalismo deve ser o objeto de nossa teorização, enquanto o método de inquirição deve ser o materialismo histórico-geográfico." A proposta é ambiciosa e difícil de fazer, como aponta o autor. No entanto, de fundamental validade para o aprofundamento dos estudos sobre as contradições capitalistas no período atual.

\section{DO ESPAÇO FIXO AO ESPAÇO DIALÉTICO}

O espaço desde a sistematização acadêmica da geografia como ciência no século XIX foi compreendido como fixo e separado da sociedade, visto como um palco onde se desenvolviam e se organizavam as relações históricas. Para Soja (1993) enquanto o tempo era tratado dialeticamente, o espaço tendia a ser visto como fixo, morto e não-dialético. A referida tendência obstruiu uma sensibilidade crítica à espacialidade que vê o mundo não apenas como construção histórica, mas também 
como construções geográficas onde o ser social está ativamente posicionado no espaço e no tempo. A espacialidade, a temporalidade e o ser social em conjunto envolvem todas as facetas da existência humana, produzem a realidade empírica e são simultaneamente produzidos por ela.

Carlos (2009, 2011a, 2011b), também elaborou uma significativa discussão sobre a produção do espaço, analisou a espacialidade como imanente à existência constitutiva da sociedade e evidenciou ser necessário considerar a reprodução da sociedade, em sua totalidade, através da produção/reprodução do espaço.

A autora também procurou sustentação nas obras de Karl Marx e Henri Lefebvre. Sobre Marx argumentou que sua obra tem significado especial, pois permitiu refletir o sentido e a noção de produção em profundidade. A noção de produção aparece como categoria central para entender o processo capitalista:

A produção como categoria central de análise abre a perspectiva de desvendar, antes de tudo, a vida humana - a produção como atividade/ação essencial do humano - ao mesmo tempo em que permite pensa-la em cada momento, circunscrita a um determinado grau de desenvolvimento da história da humanidade, o que significa dizer que a produção se define com características comuns, em diferentes épocas, fundada em relações reais que se desenvolvem no bojo de um movimento real e, em cada momento dessa história, em suas particularidades. (CARLOS, 2011a, p. 55).

Na obra “o Capital”, Marx (1984) compreendeu o trabalho como atividade humana fundamental. Explicou que a força de trabalho ou capacidade de trabalho é o conjunto das faculdades físicas e mentais do ser humano posta em ação. É a partir do trabalho que o homem produz e no capitalismo a força de trabalho aparece como mercadoria no mercado. Isso não é natural nem comum a todos os períodos históricos. É o resultado do desenvolvimento de períodos históricos anteriores e produto de muitas revoluções econômicas.

Antes de tudo, o trabalho é um processo de que participam o homem e a natureza, processo em que o ser humano com sua própria ação, impulsiona, regula e controla seu intercâmbio material com a natureza. Defronta-se com a natureza como uma de suas forças. Põe em movimento as forças naturais de seu corpo, braços e pernas, cabeça e mãos, a fim de apropriar-se 
dos recursos da natureza, imprimindo-lhes forma útil à vida humana. Atuando assim sobre a natureza externa e modificando-a, ao mesmo tempo modifica sua própria natureza. (MARX, 1984, p. 202).

A produção, mediada pelo trabalho, é dinâmica e fundada em relações reais, o que lhes dão características diferentes em tempos históricos distintos. O homem modifica a natureza e modifica também sua própria natureza, estabelecendo relações cada vez mais complexas. Embasado no conceito de produção como categoria de análise marxista, Lefebvre remeteu a discussão para o espaço e desenvolve o conceito de produção do espaço:

Lefebvre, em vários momentos de sua longa obra, insiste na dupla determinação da noção de produção: de um lado, a produção de objetos, produtos, mercadorias (o que significa dizer que o processo gera um mundo objetivo) e também a produção do espaço como condição da reprodução da vida social. Aqui, a prática sócio-espacial aponta para essa objetividade. De outro lado, a noção de produção contempla o processo de subjetivação: a produção do mundo da mercadoria, com sua linguagem e representação. Mas, ao mesmo tempo em que o homem produz o mundo objetivo (real e concreto), produz igualmente uma consciência sobre si - assim ele se produz no processo, como humano, consciência, desejos; um mundo de determinações e possibilidades capaz de metamorfosear a realidade (como possibilidade de realização do negativo). (CARLOS, 2011a, p. 56).

Lefebvre (1974), na obra "La Production de l'espace" designou ao espaço uma materialidade fundamental estabelecendo um vínculo indissociável com a produção e reprodução da vida social, uma conexão essencial entre a espacialidade e o ser. O espaço é socialmente produzido e onde se reproduzem as relações sociais.

As ideias expostas possibilitam a geografia entender melhor as relações sociais estabelecidas no modo de produção capitalista. O espaço deixou de ser compreendido apenas como palco das ações humanas, como espaço fixo; para ser compreendido a partir de relações dialéticas mais abrangentes.

Em seus sentidos mais profundos, a produção de relações mais abrangentes, e no plano espacial, significa neste contexto o que se passa fora do âmbito específico da produção de mercadorias e do mundo do trabalho (sem, todavia, deixar de incorpora-lo), 
para estender-se ao plano do habitar, do lazer e da vida privada, expandindo sua exploração pela incorporação de espaços cada vez mais amplos. Assim, se o espaço é condição da realização do processo produtivo, unindo os atos de distribuição, troca e consumo de mercadorias, ele se produz como materialidade como, por exemplo, infraestrutura viária, rede de água, luz e esgoto etc. todavia, o espaço guarda o sentido do dinamismo das necessidades e dos desejos que marcam a reprodução da sociedade em seu sentido mais amplo, a realização da vida para além de sua sobrevivência. Os fundamentos da reprodução que, como afirmamos, contempla uma especificidade histórica, hoje se explicam como uma produção capitalista. (CARLOS, 2011a, p. 56).

Dentro dessa discussão Soja (1993) procurou apresentar uma sequência de premissas que explicam como a constituição da sociedade é espacial e temporal:

1. A espacialidade é um produto social consubstanciado e reconhecível, parte de uma "segunda natureza" que incorpora, ao socializá-los e transformá-los, os espaços físicos e psicológicos.

2. Como produto social, a espacialidade é, simultaneamente, o meio e o resultado, o pressuposto e a encarnação da ação e da relação sociais.

3. A estruturação espaço-temporal da vida social define o modo como a ação e a relação sociais (inclusive as relações de classe) são materialmente constituídas, concretizadas.

4. O processo de constituição/concretização é problemático, repleto de contradições e de lutas (em meio a muitas coisas recorrentes e rotinizadas).

5. As contradições decorrem, primordialmente, da dualidade do espaço produzido, como resultado/encarnação/produto e meio/pressuposto/

produtor da atividade social.

6. A espacialidade concreta - a geografia humana efetiva - é, pois, um terreno competitivo de lutas pela produção e reprodução sociais, de práticas sociais que visam, quer à manutenção e reforço da espacialidade existente, quer a uma reestruturação significativa e/ou a uma transformação radical.

7. A temporalidade da vida social, desde as rotinas e eventos da atividade cotidiana até a construção da história em prazo mais longo (évènement $e$ durée, para usarmos a linguagem de Braudel), radica-se na contingência espacial, exatamente do mesmo modo que a espacialidade da vida social se enraíza na contingência temporal/histórica.

8. A interpretação materialista da história e a interpretação materialista da geográfica são inseparavelmente entremeadas e

Geo UERJ. Rio de Janeiro - Ano 16, nº. 25, v. 2, $2^{\circ}$ semestre de 2014, pp.37-56

ISSN: 1415-7543 E-ISSN: 1981-9021

http://www.e-publicacoes.uerj.br/index.php/geouerj 
teoricamente concomitantes, sem nenhuma priorização intrínseca de uma em relação à outra. (SOJA, 1993, p. 158159).

As premissas levantadas, segundo o autor, tomadas em conjunto estruturam uma interpretação dialética do espaço no qual a produção do espaço em conjunto com a construção da história são descritas como o meio e o resultado, a pressuposição e a encarnação da ação e dos relacionamentos sociais. O espaço é considerado como condição para a realização da produção, mais do que isso, é condição para a reprodução da sociedade para além da sua sobrevivência.

O espaço é produzido por agentes reais com interesses e estratégias delimitadas. Os interesses entram muitas vezes em conflitos, pois as classes sociais historicamente definidas possuem objetivos divergentes. As condições estabelecidas pelo capitalismo sociedade dividida em classes contraditórias e a valorização como finalidade - atuam como determinações para a (re)produção do espaço, que deve ser compreendido como realidade em construção, em transformação e em continuo movimento dialético.

\section{A VALORIZAÇÃO DO ESPAÇO E A ACUMULAÇÃO DE CAPITAL}

Para entendermos o valor que o espaço adquire no modo de produção capitalista vamos verificar inicialmente como ocorreu a acumulação primitiva. Quaini (1979, p. 66) apresentou a seguinte argumentação: “[...] em termos geográficos pode ser expressa como progressiva dissociação do homem em relação ao território, após a transformação do território de valor de uso em valor de troca ou mercadoria." O território se transformou em mercadoria sob a orientação capitalista, pois apresenta valor de troca, sendo a maior parte da população expropriada ou espoliada. Segundo Marx (1985):

O processo que cria o sistema capitalista consiste apenas no processo que retira ao trabalhador a propriedade de seus meios de trabalho, um processo que transforma em capital os meios sociais de subsistência e os de produção e converte em assalariados os produtores diretos. A chamada acumulação primitiva é apenas o processo histórico que dissocia o trabalhador dos meios de produção. É considerada primitiva porque constitui a pré-história do capital e do modo de produção capitalista. (MARX, 1985, p. 830).

Geo UERJ. Rio de Janeiro - Ano 16, nº. 25, v. 2, $2^{\circ}$ semestre de 2014, pp.37-56

ISSN: 1415-7543 E-ISSN: 1981-9021

http://www.e-publicacoes.uerj.br/index.php/geouerj 
Ainda para Marx (1985, p. 831) “A expropriação do produtor rural, do camponês, que fica privado de suas terras, constitui a base de todo o processo." A terra se tornou propriedade privada e mercadoria que pode ser comprada e vendida e está concentrada nas mãos de poucos. O principio da produção sob o capitalismo é que tanto a força de trabalho como as condições e meios de trabalho se tornem mercadorias.

A ocupação e a apropriação podem ser consideradas como momento prévio para a valorização. A fixação deu inicio a produção e o excedente de trabalho de gerações sucessivas possibilitou a acumulação de trabalho. Em um segundo momento ocorreram os movimentos de expansão, sendo o Estado, geralmente, o gestor da política territorial e o promotor da expansão estimulada pela ação do capital que necessita de reprodução ampliada. O processo de colonização atuou na ampliação e expansão das relações econômicas ao anexar novos territórios no circuito produtivo.

A expansão territorial e a valorização capitalista produzem espaços com características próprias, porém inseridos em um processo mais amplo que é caracterizado pela dialética entre o local e o global, entre a singularidade e a universalidade.

No capitalismo os espaços são continuamente produzidos e reproduzidos através do trabalho social, porém não apresentam a mesma capacidade de valorização. O que se verifica é o direcionamento dos maiores investimentos para os espaços que o capitalista julga de maior potencialidade. Desta madeira o capital se movimenta na procura dos espaços que melhor atendem as suas necessidades.

O que determina a disposição ou não do capital em se instalar neste ou naquele espaço é muito mais a "viabilidade" econômica da produção que se pretende realizar ali. [...] É sabido que o capital tem condições (técnicas) de subverter o papel dos chamados obstáculos naturais à produção; contudo, o que vai definir se ele realizará ou não a valorização de determinados espaços é a sua possibilidade de autovalorizar-se. (MORAES; COSTA, 1999, p. 178).

A ação do capital tem como objetivo a valorização. Isso faz com que os investimentos sejam dirigidos para onde existem melhores condições, segundo os interesses capitalistas e conforme as necessidades e recursos disponíveis, o que conduz ao desenvolvimento desigual. Os obstáculos naturais não são grandes empecilhos para 
o capital, visto que os avanços nos meios de comunicação e transportes permitem a apropriação de praticamente qualquer território para a produção. O que realmente vai definir a atuação são as possibilidades de retorno. Dentro desta lógica:

Pode-se afirmar que as determinações gerais do capitalismo na sua relação com o espaço, substantivam um modo geral de valoriza-lo que poderíamos definir como uma verdadeira valorização da valorização. Sob esse modo de produção, o espaço é, antes de tudo, objeto, veículo e produto do capital. Por isso mesmo, em termos de determinações gerais, o processo de valorização capitalista do espaço não é outro que a própria valorização do capital. Por outro lado, como o espaço real é um atributo da materialidade, o próprio movimento do capital, enquanto história de homens e lugares reais, manifesta-se espacialmente desigual. (MORAES; COSTA, 1999, p. 168).

No capitalismo o que interessa é a acumulação de capital e não de espaço, mesmo que o espaço seja uma necessidade e uma condição para a valorização, a mobilidade do capital ou transferência geográfica de valor tornou possível seu deslocamento em busca da ampliação dos lucros.

Tudo o que é necessário para definir uma transferência geográfica de valor é dar ao capitalismo uma geografia concreta, deslocar a produção e a troca da cabeça a-espacial de um alfinete para uma espacialidade diferenciada e desigualmente desenvolvida. $\mathrm{Na}$ paisagem geográfica do capital, existem áreas de maior e menor produtividade, razões capital/trabalho altas e baixas (ou seja, a composição orgânica), e taxas variáveis de lucro, todas dentro do mesmo mercado integrado de mercadorias. Assim, as trocas de mercado transformam-se num veículo, não somente de transferência de valor entre empresas e setores, mas também de uma transferência geográfica de valor. Algumas áreas obtêm um lucro líquido em termos de valor, enquanto outras incorrem num prejuízo líquido, e isso tem um certo efeito na geografia da acumulação, na formação de centros e periferias em todas as escalas espaciais. (SOJA, 1993, p. 139).

A transferência geográfica de valor é o processo onde uma parte do valor produzido em um local é realizado em outro, agregando-se a acumulação da região receptora. Sobre a tensão entre fixidez e movimento do capital Harvey (1984), analisou que:

Geo UERJ. Rio de Janeiro - Ano 16, n. 25, v. 2, $2^{\circ}$ semestre de 2014, pp.37-56

ISSN: 1415-7543 E-ISSN: 1981-9021

http://www.e-publicacoes.uerj.br/index.php/geouerj 
The tensions between fixity and motion in the circulation of capital, between concentration and dispersal, between local commtiment and global concerns, put immense strains upon the organization capacities of capitalism. The history of capitalism has, as a consequence, been marked by continuous exploration and modification of organizational arrangements that can assuage and contain such tensions. The result has been the creation of nested hierarchical structures of organization which con link the local and particular with the achievement of abstract labour on the world stage. (HARVEY, 1984, p. 422).

O capital na procura de ampliação dos lucros produz/reproduz, valoriza ou desvaloriza o espaço. Para o capital não há constrangimento em se retirar de um país, de um estado ou de um município para se instalar em outro, desde que exista a possibilidade de mobilidade, que é mais rígida em alguns setores e mais flexível em outros.

Assim, entendemos que o capital produz e reproduz espaço com o objetivo de ampliar os lucros. Contudo, contraditoriamente a ação do capital existe resistência estabelecida por determinados grupos sociais organizados. Essa resistência também pode produzir espaço.

\section{A PRODUÇÃO DO ESPAÇO COMO RESISTÊNCIA}

Existem indicativos suficientes que permitem afirmar que o processo de produção do espaço também se manifesta como reação aos interesses do capital em busca de reprodução ampliada. Se a ação expansiva do capital é motivada pela ampliação e em virtude das novas técnicas apresenta uma amplitude global (bem como local), concentradora e centralizadora; a reação se manifesta, pelo menos inicialmente, a partir do local. No entanto, seus desdobramentos gradualmente vão ganhando amplitude.

É na escala local que uma parcela da população reconhece a exploração desmedida imposta pelos grupos que controlam a informação, as finanças, a produção de mercadorias e as técnicas e procuram se organizar com o objetivo direto ou indireto de oferecer resistência. A resistência ocorre mediante um compromisso firmado entre 
aqueles que integram o grupo e decidem colocar em prática ações transformadoras. No processo a submissão é substituída pela motivação e pela criatividade.

Entre os inúmeros exemplos o Movimento dos Trabalhadores Rurais Sem Terra - MST, é esclarecedor. O movimento foi criado na década de 1980, como resistência a desapropriação causada pela construção de barragens. Conforme Fernandes (2008, p. 02,) “[...] o movimento definiu o seu primeiro encontro realizado em janeiro de 1984, na cidade de Cascavel, estado do Paraná, como a data de sua fundação.” Suas ações ganharam amplitude e atualmente vão alem das fronteiras do país.

[...] o MST vai disputar territórios com seu principal oponente: o agronegócio. Essa disputa é uma das principais marcas da questão agrária desde o passado até a atualidade e foi ampliada e intensificada pela modernização e mundialização da produção agrícola. Contraditoriamente, esta nova realidade liberta a reforma agrária da simples compreensão distribucionista e amplia seu conteúdo para uma luta ampla, multidimensional e complexa. Lutar pela reforma agrária, significa lutar por todas as dimensões do território, entre eles a tecnologia, o mercado, a educação, saúde e, principalmente, contra o capital que procura tomar o controle dos territórios do campesinato (FERNANDES, 2008, p. 03).

Os acampamentos e os assentamentos são espaços revolucionários produzidos socialmente mediante o trabalho. A concentração fundiária é histórica no país, um pequeno número de proprietários possui vasta quantidade de terra, sendo que uma boa parte é ociosa. Entre as ideias defendidas pelo MST está a produção do assentamento como um espaço para as famílias camponesas trabalharem e produzirem, garantindo a função social da terra e a produção de alimentos.

O maior desafio é combater a concentração fundiária e conter a expansão e influencia política e econômica exercida pelo agronegócio. O MST é o maior movimento na luta pela terra no país e responde por cerca de $60 \%$ das famílias que lutam pelo acesso a terra. Existem outros movimentos importantes atuando contra a concentração de terras, entre eles a Confederação Nacional dos Trabalhadores na Agricultura - CONTAG, Comissão Pastoral da Terra - CPT, Movimento dos Pequenos Agricultores - MPA, Movimento de Luta pela Terra - MCT, Movimento de Mulheres Camponesas - MMC, entre muitos outros. 
O movimento dos Trabalhadores Sem Teto - MTST é outro exemplo de luta contra o capital. Surge na década de 1990, com o objetivo de garantir o direito a habitação. A ação do capital procura valorizar o solo urbano através de especulação imobiliária, com isso, significativa parcela da população não tem acesso a um direto básico que é a habitação com dignidade. Nas grandes metrópoles, assim como nas cidades médias, o capital associado ao Estado estabelece formas de valorização do solo para especulação impedindo que os mais pobres tenham acesso a moradia. O MTST luta contra a especulação ocupando moradias ociosas e se contraponto a concentração de riqueza.

É nítido no país, especialmente nas grandes e médias cidades, o poder e controle exercido por determinados grupos que controlam o solo urbano. O preço do metro quadrado atinge valores absurdos e a população com menor renda não tem acesso a determinados setores da cidade, sendo empurrada para bairros distantes carentes em infraentrutura. Enquanto um pequeno grupo acumula riqueza, parcela significativa da população tem que se deslocar por longas distâncias através de um transporte caro e de baixa qualidade. O MTST não luta apenas pelo direito a moradia, o movimento combate e se engaja pelo direito a cidade.

Villaça (2011), realizou um amplo estudo sobre a segregação urbana e a desigualdade na cidade de São Paulo revelando a relação entre a segregação residencial e a segregação dos locais de emprego. Demonstrou que a segregação estabelece um ônus para a população mais pobre e uma grande vantagem para os mais ricos.

A associação de moradores é outra forma de organização popular com a finalidade de discutir os problemas de infraestrutura, saúde, segurança, educação, etc. existentes no bairro. Quando atuantes e democráticas as associações de moradores se constituem em espaços democráticos de consciência e luta pelos direitos dos moradores.

A perspectiva democrática, o engajamento social e a participação popular são os méritos da associação de moradores. O compromisso com o lugar abre as portar para uma ação transformadora consistente que podem viabilizar novos canais de comunicação para ampliar o movimento a exemplos das rádios e tevês comunitárias que divulgam informações sobre o bairro.

Já a economia solidária procura romper com as amarras impostas pelo capital e construir uma sociedade centrada nos seres humanos. Entende o trabalho como uma 
forma de libertação estabelecendo uma alternativa à dimensão alienante das relações do trabalho capitalista. Envolve a dimensão social, econômica, política, ecológica e cultural. Para Singer (2002):

A economia solidária é outro modo de produção, cujos princípios básicos são a propriedade coletiva ou associada do capital e o direito à liberdade individual. A aplicação desses princípios une todos os que produzem numa única classe de trabalhadores que são possuidores de capital por igual em cada cooperativa ou sociedade econômica. O resultado natural é a solidariedade e a igualdade [...]. (SINGER, 2002, p. 10,).

Enquanto a economia capitalista aplica o modelo de gestão hierárquica onde as ordens fluem de cima para baixo a economia solidária propõe a autogestão, ou seja, um modelo mais democrático. A economia solidária se apresenta como uma alternativa as contradições do capitalismo.

A economia solidária é ou poderá ser mais do que mera resposta à incapacidade do capitalismo de integrar em sua economia todos os membros de sociedade desejosos e necessitados de trabalhar. Ela poderá ser o que em seus primórdios foi concebida para ser: uma alternativa superior ao capitalismo. Superior não em termos econômicos estritos, ou seja, que as empresas solidárias regularmente superariam suas congêneres capitalistas, oferecendo aos mercados produtos ou serviços melhores em termos de preço e/ou qualidade. A economia solidária foi concebida para ser uma alternativa superior por proporcionar às pessoas que a adotam, enquanto produtoras, poupadoras, consumidoras etc., uma vida melhor. (SINGER, 2002, p. 114. Grifo do autor).

Os exemplos escolhidos, entre outros que também são demasiadamente importantes, evidenciam que a produção do espaço é um movimento dialético tencionado cada vez mais pela contradição entre a ação do capital e os movimentos de resistência.

\section{CONSIDERAÇÕES FINAIS}

Enquanto o processo de produção do espaço comandado pela ação do capital tem por finalidade o controle do território, a ampliação de lucros e beneficia 
financeiramente um pequeno grupo capaz de controlar e articular a produção e as finanças; os agentes sociais produtores do espaço como resistência estabelecem outras prioridades. As ações citadas no artigo como resistência não são apenas articulações teóricas, são praticas efetivas produtoras de espaço sob outra perspectiva política, econômica e até mesmo cultural.

Ao produzir um espaço que se manifesta como resistência os movimentos sociais citados articulam um processo inovador capaz de gerar uma tensão cada vez maior frente as praticas já estabelecidas. Tal tensão procura romper com o establishment e abre as portas para uma revolução pautada na substituição de um modelo centralizador baseando na acumulação, para um modelo que priorize os seres humanos através de atitude crítica e emancipadora.

\section{REFERÊNCIAS}

CARLOS, Ana Fani Alessandri. A (re)produção do espaço urbano. São Paulo: Editora da Universidade de São Paulo, 2008.

CARLOS, Ana Fani Alessandri. Da "organização" à "produção" do espaço no movimento do pensamento geográfico. In: CARLOS, Ana Fani Alessandri; SOUZA, Marcelo Lopes de; SPOSITO, Maria Encarnação Beltrão. A produção do Espaço Urbano: Agentes e processos, escalas e desafios. São Paulo: Contexto, 2011a.

CARLOS, Ana Fani Alessandri. A condição espacial. São Paulo: Contexto, 2011b.

CORRÊA, Roberto Lobato. Sobre agentes sociais, escala e produção do espaço: um texto para discussão. In: CARLOS, Ana Fani Alessandri; SOUZA, Marcelo Lopes de; SPOSITO, Maria Encarnação Beltrão. A produção do Espaço Urbano: Agentes e processos, escalas e desafios. São Paulo: Contexto, 2011.

FERNANDES, Bernardo Mançano. O MST e as reformas agrárias do Brasil. Boletim DATALUTA. Dez. 2008. Disponível em: http://docs.fct.unesp.br/nera/artigodomes /12artigodomes_2008.pdf. Acesso em 25 de setembro de 2012.

FRIGOTTO, Gaudêncio. O enfoque da dialética materialista histórica na pesquisa educacional. In: FAZENDA, I. (Org.) Metodologia da pesquisa educacional. São Paulo: Cortez, 1989.

HARVEY, David. The Limits to Capital. Oxford: British Library, 1982.

HARVEY, David. A produção capitalista do espaço. São Paulo: Annablume, 2006a. 
KESSLER, Jean. Prefácio. In: MARX, Karl. Miséria da Filosofia. São Paulo: Martin Claret, 2007.

KOSIK, Karel. Dialética do concreto. Rio de Janeiro: Paz e Terra, 1976.

LEFEBVRE, Henri. La production de l'espace. Paris: Éditions Anthropos, 1974.

LEFEBVRE, Henri. O Marxismo. São Paulo: Difel/Difusão Editorial. 1979.

LEFEBVRE, Henri. Lógica formal Lógica dialética. Rio de Janeiro: Civilização Brasileira, 1983.

LÖWY, Michael. A teoria do desenvolvimento desigual e combinado. In: LÖWY, Michael; BENSAID, Daniel. Marxismo, modernidade e utopia. São Paulo: Xamã, 2000.

LUKACS, György. Ontologia do ser social: os princípios ontológicos fundamentais de Marx. São Paulo: Livraria Editora Ciências Humanas, 1979.

MARX, Karl. O capital: crítica da economia política. Livro 1 - o processo de produção do capital. Volume 1. São Paulo: Difel, 1984.

MARX, Karl. O capital: crítica da economia política. Livro 1 - o processo de produção do capital. Volume 2. São Paulo: Difel, 1985.

MARX, Karl; ENGELS, Friedrich. Manifesto do partido comunista. Porto Alegre: L\&PM, 2007.

MARX, Karl; ENGELS, Friedrich. A ideologia Alemã. São Paulo: Expressão Popular, 2009.

MORAES, Antonio Carlos Robert; COSTA, Wanderley Messias da Costa. Geografia Crítica: a valorização do espaço. São Paulo: Editora Hucitec, 1999.

QUAINI, Massimo. Marxismo e Geografia. Rio de Janeiro: Paz e Terra, 1979.

SINGER, Paul. Introdução à Economia Solidária. São Paulo: Editora Fundação Perseu Abramo, 2002.

SMITH, Neil. Desenvolvimento desigual: natureza, capital e a produção de espaço. Rio de Janeiro: Bertrand Brasil, 1988.

SOJA, Edward. Geografia Pós-Moderna: A reafirmação do espaço na teoria social crítica. Rio de Janeiro: Jorge Zahar, 1993.

VILLAÇA, Flávio. São Paulo: segregação urbana e desigualdade. Estudos Avançados Vol.25 no.71. São Paulo Jan./Apr. 2011. Disponível em: http://www.scielo.br/scielo. 
php?pid=S0103-40142011000100004\&script=sci_arttext. Acesso: 20 de outubro de 2012.

Artigo recebido para publicação em maio de 2014.

Artigo aceito para publicação em outubro de 2014.

Geo UERJ. Rio de Janeiro - Ano 16, $\mathrm{n}^{\circ}$. 25, v. 2, $2^{\circ}$ semestre de 2014, pp.37-56

ISSN: $1415-7543$ E-ISSN: $1981-9021$

http://www.e-publicacoes.uerj.br/index.php/geouerj 